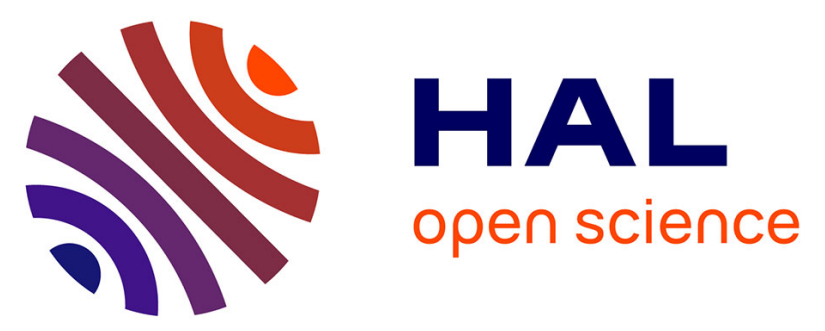

\title{
Automated external defibrillator use in out-of-hospital cardiac arrest: Current limitations and solutions
}

Clémence Delhomme, Mario Njeim, Emilie Varlet, Louis Pechmajou, Nordine

Benameur, Pascal Cassan, Clément Derkenne, Daniel Jost, Lionel Lamhaut, Eloi Marijon, et al.

\section{To cite this version:}

Clémence Delhomme, Mario Njeim, Emilie Varlet, Louis Pechmajou, Nordine Benameur, et al.. Automated external defibrillator use in out-of-hospital cardiac arrest: Current limitations and solutions. Archives of cardiovascular diseases, 2019, 112, pp.217 - 222. 10.1016/j.acvd.2018.11.001. hal-03485986

\section{HAL Id: hal-03485986 \\ https://hal.science/hal-03485986}

Submitted on 20 Dec 2021

HAL is a multi-disciplinary open access archive for the deposit and dissemination of scientific research documents, whether they are published or not. The documents may come from teaching and research institutions in France or abroad, or from public or private research centers.
L'archive ouverte pluridisciplinaire HAL, est destinée au dépôt et à la diffusion de documents scientifiques de niveau recherche, publiés ou non, émanant des établissements d'enseignement et de recherche français ou étrangers, des laboratoires publics ou privés.

\section{(c) (1) $\$$}

Distributed under a Creative Commons Attribution - NonCommercial| 4.0 International 


\section{Automated external defibrillator use in out-of-hospital cardiac arrest: Current limitations and solutions}

Abbreviated title: Automated external defibrillators

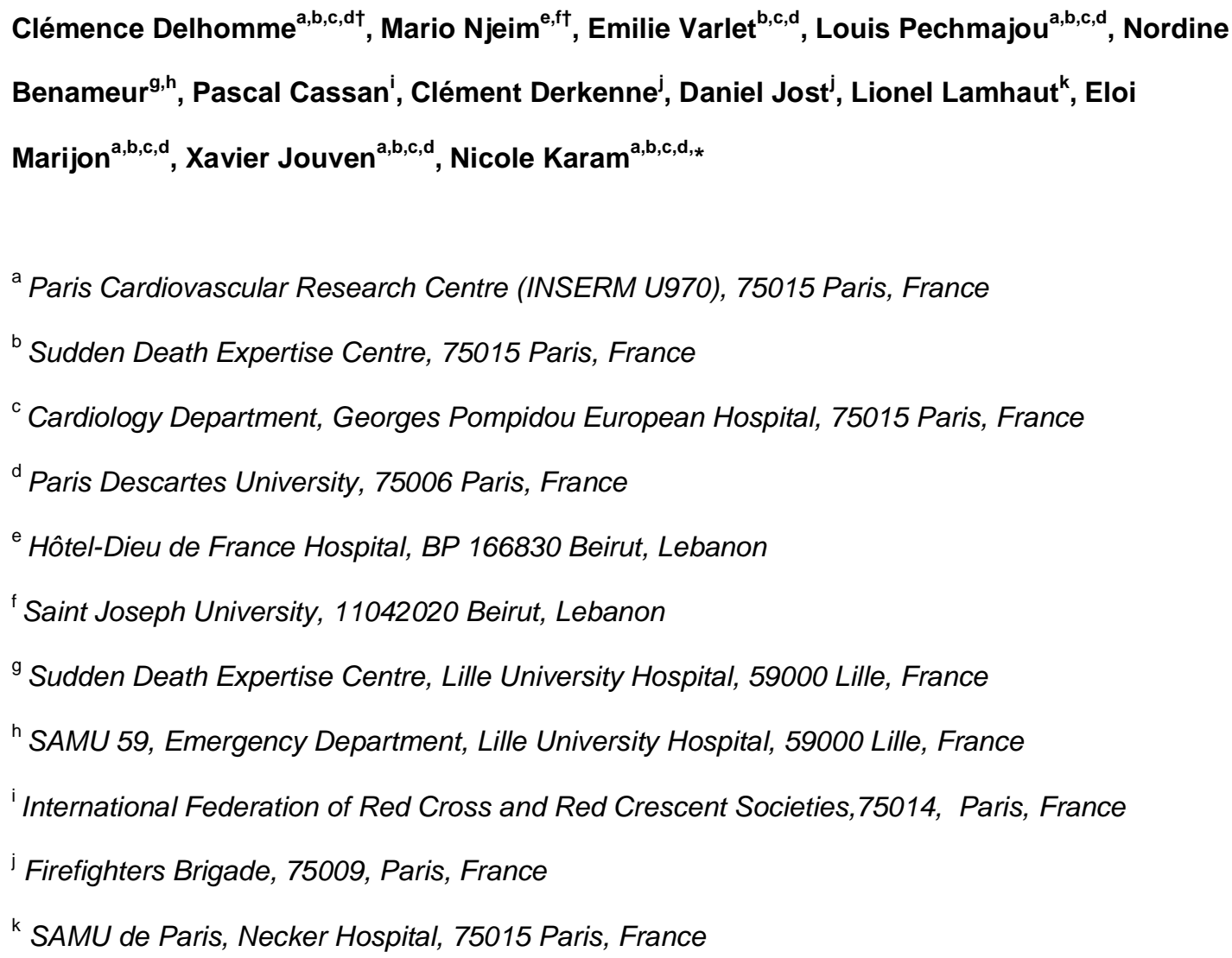

Corresponding author at: Sudden Death Expertise Centre, Paris Cardiovascular Research Centre (INSERM U970), European Georges Pompidou Hospital, 56 Rue Leblanc, 75987 Paris Cedex 15, France.

E-mail address: nicole.karam@aphp.fr (N. Karam).

${ }^{\dagger}$ Clémence Delhomme and Mario Njeim contributed equally to this paper. 


\section{Summary}

Out-of-hospital sudden cardiac arrest (OHCA) is a major public health issue, with a survival rate at hospital discharge that remains below $10 \%$ in most cities, despite huge investments in this domain. Early basic life support (BLS) and early defibrillation using automated external defibrillators (AEDs) stand as key elements for improving OHCA survival rate. Nevertheless, the use of AEDs in OHCA remains low, for a variety of reasons, including the number, accessibility and ease of locating AEDs, as well as bystanders' awareness of BLS manoeuvres and of the need to use AEDs. Several measures have been proposed to improve the rate of AED use, including optimization of AED deployment strategies as well as the use of drones to bring the AEDs to the OHCA scene and of mobile applications to locate the nearest AED. If they are to be effective, these measures should be combined with large communication campaigns on OHCA, and wide-scale education of the public in BLS and AEDs, to reduce the burden of OHCA.

\section{Résumé}

L'arrêt cardiorespiratoire (ACR) extrahospitalier constitue un véritable problème de santé publique, avec un taux de survie qui reste inférieur à $10 \%$ dans la plupart des pays, malgré de considérables investissements dans ce domaine. La réanimation précoce et une défibrillation précoce grâce à l'usage des défibrillateurs automatiques externes (DAE) ont été identifiées comme des éléments clés pour améliorer la survie des ACR. Pourtant, le taux d'utilisation des DAEs dans les ACR reste faible. Plusieurs limites empêchent une plus ample utilisation des DAE, dont leur nombre, leur accessibilité et la facilité de leur localisation, ainsi que l'éducation des témoins aux gestes qui sauvent et à la nécessité d'utiliser un DAE. Plusieurs pistes ont été testées pour améliorer ces différents paramètres, incluant une optimisation du déploiement des DAEs, ainsi que l'utilisation de drones permettant de ramener les DAEs sur le site d'ACR et d'applications permettant de localiser le DAE le plus proche. Ces mesures doivent systématiquement être associées à de vastes campagnes de communication sur la mort subite et à une éducation du grand public aux manœuvres de réanimation et à l'intérêt de l'utilisation des DAEs.

\section{KEYWORDS}

Automated external defibrillation; 
Sudden cardiac arrest;

Outcome;

Public access defibrillation

\section{MOTS CLÉS}

Arrêt cardiaque ;

Défibrillation grand public ;

Défibrillateurs automatiques externes ;

Pronostic

Abbreviations: AED, automated external defibrillator; BLS, basic life support; CPR, cardiopulmonary resuscitation; EMS, emergency medical services; OHCA, out-of-hospital sudden cardiac arrest. 


\section{Background}

Out-of-hospital sudden cardiac arrest (OHCA) is a major public health issue, with more than 350,000 deaths per year in the USA and 50,000 deaths per year in France, accounting for almost half of cardiovascular mortality [1-5]. Despite huge investments, the increase in survival rates is limited $[6,7]$ and outcomes remain poor, with an overall survival rate to hospital discharge of $<10 \%[8]$.

Several strategies have been developed to improve OHCA prognosis. Among them, basic life support (BLS) manœuvres, including cardiopulmonary resuscitation (CPR) and early defibrillation, were identified as key elements for successful resuscitation (Fig. 2) [9-11]. However, the rate of AED use remains extremely low worldwide, and is $<5 \%$ in France $[12,13]$. Efforts are being made to improve OHCA management and to increase the availability and use of automated external defibrillators (AEDs). A French law was passed in June 2018 to enforce AED deployment at specific sites, impose regular maintenance for existing AEDs and create a national public AED map, by locating AEDs already deployed in France [14].Two other proposed laws for optimizing AED deployment and use were submitted in 2018. In this review, we provide a broad picture of the current limitations to wider AED use in France, and offer solutions that could help to optimize AED deployment and increase their use.

\section{AED use: Yield and current status}

Rapidity of defibrillation is a key factor in its success, as the probability of survival decreases by 10 $12 \%$ per minute of delay in defibrillation $[15,16]$. Community strategies aiming to reduce the time to defibrillation in those experiencing an OHCA include equipping and training first responders (firefighters), Emergency Medical Services (EMS) personnel and paramedics, as well as placing AEDs in busy locations such as airports, train stations, commercial aircraft and gambling casinos, and educating the public in the use of AEDs [17-20]. Accordingly, the concept of Public Access Defibrillation Programmes emerged in North America in the mid-1990s to promote deployment of AEDs and education of the public in BLS [21-23]. Since then, Public Access Defibrillation Programmes have also been recommended in Europe, and have gained international support [24-26].

Several trials have confirmed the benefit of AED deployment and use. In Austria, Fleischhackl et al. compared OHCA outcomes before and after AED deployment; they observed a more than fivefold increase in survival at hospital discharge, from $4.3 \%$ before the installation of AEDs to $27 \%$ afterwards 
[27]. Berdowski et al. showed that the use of AEDs reduced the time to first shock from 11 to 4.1 minutes [28]. Compared with providing CPR alone while awaiting the arrival of EMS personnel, the use of AEDs was associated with a doubling in the number of neurologically intact OHCA survivors when laypersons were trained and equipped to provide early CPR and use AEDs [17].

In France, legislation passed in 2007 authorized the use of AEDs by all-comer bystanders, regardless of whether they were trained to use an AED. However, the rate of AED use in OHCA remains extremely low, not exceeding $2 \%$ in Paris and its suburbs, and $4 \%$ in France $[12,13]$. The low rate of $A E D$ use by OHCA bystanders can be explained by a number of limiting factors related to the availability of functional AEDs and the bystanders' awareness and willingness to use AEDs (Fig 1, Central Illustration).

\section{AED deployment: Issues and solutions}

The availability of an AED near the OHCA site is one of the main limitations. In a study analysing the dissemination of AEDs in France, we observed marked regional disparities, with AED densities varying from 5 to 3399 per 100,000 inhabitants per $1000 \mathrm{~km}^{2}$. AED density correlated strongly with mean survival rates, which ranged from $8 \%$ in areas with an AED density below the median to $18 \%$ in areas with an AED density above the median, with a 125\% higher survival rate in areas with a high AED density $(P<0.001)$ [29]. A more homogeneous deployment of AEDs across the French territory is therefore required.

The ease of locating AEDs and their accessibility are other potential limitations to wider AED use. In a sample population in Southampton in the UK, only $5 \%$ of interviewed individuals were aware of where or how to find the nearest AED [30]. Furthermore, Hansen et al. showed that AEDs were inaccessible in $54 \%$ of OHCA cases occurring during the evening, night-time and weekends, despite being within walking distance of the OHCA site [31]. The selection of AED location is therefore a delicate issue. Current European Resuscitation Council guidelines recommend AED placement in locations where OHCAs occur at least every 5 years [25]. The main limitation of such a systematic strategy is that it leads after a few years to an unlimited increase in the number of deployed defibrillators, accompanied by minimal improvements in the OHCA-to-AED distance. In addition, the exact AED location might be difficult to guess by the bystanders once an OHCA has occurred. 
To identify the ideal way to optimize AED placement, we compared the current recommended strategy with two novel AED deployment strategies in Paris, according to the expected number of deployed AEDs and the average expected OHCA-to-AED distance. The first strategy was grid-based, with AEDs supposed to be placed at regular fixed distances, ranging from 200 to $2000 \mathrm{~m}$. The second strategy was landmark-based, in which we tested placing AEDs at different well-known and easily located landmarks: district town halls, post offices, subway stations, bike-sharing stations (Velib') or pharmacies. This landmark-based strategy resulted in the shortest OHCA-to-AED distances for the same total number of AEDs deployed. Placing AEDs at the bike-sharing stations (Velib') was the most cost-effective option among different landmark locations (Table 1). More importantly, bike-sharing stations are regularly distributed throughout Paris, easy to locate and accessible at all hours, unlike schools and businesses, where the AEDs would not be accessible outside normal business hours [29, 32].

Other solutions to the difficulty in locating and obtaining AEDs have been proposed. Among them, the use of drones to deliver an AED to the site of an OHCA has been considered [33]. Claesson et al. showed that this strategy is safe and efficacious, particularly in rural areas, where the drones arrived before the EMS in $93 \%$ of cases, with a mean saving of 19 minutes [34]. Several cities have also developed the concept of dispatch-assisted defibrillation, in which a text message is sent requesting volunteers once an OHCA has occurred, specifying the location of the OHCA and the nearest AED. Early experience in the Netherlands in 2013 showed a reduction in time to defibrillation of 2 minutes and 39 seconds compared with the EMS [35]. In France, several smartphone applications have also been developed to notify volunteers of the occurrence of an OHCA and the nearest AED location [36]. The effectiveness of these applications has yet to be assessed.

Dispatch centres can also guide bystanders to locate the nearest AED. Guidelines recommend that $A E D$ registries providing the geographic location of $A E D$ s are linked to dispatch centres as tools to refer callers to nearby AEDs. The guidelines also advocate that the dispatchers expand the role of bystanders into AED use [16]. In France, the exact number and locations of deployed AEDs are unknown. New legislation was issued in June 2018 recommending the creation of a national map of deployed AEDs, which could help the dispatchers to locate the nearest AED [14]. Besides addressing the issue of AED location, this same law enforced the obligation to regularly maintain deployed AEDs. Despite the absence of official numbers, several cases of failing AEDs identified during an OHCA 
have been reported worldwide, underlining the need for regular controls over those devices once placed.

\section{Bystander-related issues and solutions}

Besides the availability and accessibility of AEDs, the ability of bystanders to recognize an OHCA and their awareness of the need to initiate CPR and use an AED are other key factors that still need to be improved. American and European recommendations insist on the importance of promptly initiating the OHCA chain of survival, which involves immediate high-quality CPR and rapid defibrillation with an AED [11, 25]. Therefore, population education in BLS and AED use is crucial for improving OHCA survival rates. We have shown significant regional disparities in the proportion of BLS-educated inhabitants within the French territory, along with the regional discrepancies in AED density described above. The proportion of BLS-educated individuals varied widely among French districts, ranging from 6955 to 36,636 per 100,000 inhabitants. Importantly, the mean survival rate was $5 \%$ in districts with a BLS-education level below the median, compared with $21 \%$ in districts with a BLS-education level above the median, corresponding to a $316 \%$ higher survival rate $(P<0.001)$. The survival rate was strikingly higher in areas with both AED density and a BLS-education level above the median (23\%) than in areas with both AED density and a BLS-education level below the median (5\%) (Fig. 3) [29].

Population education can also help to solve the problem of bystanders' unwillingness to use AEDs. The willingness of laypeople to use public-access AEDs varies markedly across studies. In a UK study, only $2 \%$ of bystanders were willing to retrieve and use an AED in case of OHCA [30]. Reasons behind this reluctance to AED use included not knowing how the device worked (40-85\%), not being comfortable using it (72-84\%), fear of causing harm to the patient and legal liability [37]. Willingness to use an AED increased in one study in the USA from $71 \%$ to $83 \%$ if the survey respondents were informed about legal liability protection for rescuers [38].

EMS dispatchers receiving a call for a suspected OHCA have an important role to play in improving the willingness of bystanders to use an AED, and in guiding them through the steps of its use once an OHCA has occurred. Regardless of whether the bystanders have never had BLS training or if this training was conducted long before the OHCA, dispatchers can still improve the rate of AED use before EMS arrival by reassuring the bystanders about the safety and practical aspects of AED use. Dispatchers should be aware of this responsibility, and trained in better recognizing an OHCA 
and guiding bystanders on the phone. Currently, the rate of referral of bystanders to the closest AED remains surprisingly low. In a Swedish study conducted in 2014, dispatch centres were provided with a tool to display AED locations and accessibility. Among OHCAs where an available AED was $<100$ m away, dispatchers referred the callers to the AED in only $4.3 \%$ of cases, highlighting the need to further educate EMS dispatchers about their responsibility to increase the rate of AED use [39].

\section{Conclusions}

Despite its major well-demonstrated benefit in improving survival rates after OHCA, the rate of AED use by OHCA bystanders remains extremely low, not exceeding $4 \%$ in France. Efforts are needed to improve the rate of $A E D$ use, including optimization of AED deployment, whether in terms of the number of AEDs deployed or the selection of AED location. This should be combined with large communication campaigns on OHCA, and wide-scale education of the public in BLS and AED use, to reduce the burden of OHCA.

\section{Sources of funding}

None.

\section{Disclosure of interest}

The authors declare that they have no conflicts of interest concerning this article. 


\section{References}

[1] Bonny A, Noah DN, Ngantcha M, et al. Epidemiology of sudden cardiac death in Cameroon: rationale and design of the Douala-SUD survey. Arch Cardiovasc Dis 2014;107:433-42.

[2] Go AS, Mozaffarian D, Roger VL, et al. Heart disease and stroke statistics--2014 update: a report from the American Heart Association. Circulation 2014;129:e28-e292.

[3] Jouven X, Bougouin W, Karam N, Marijon E. [Epidemiology of Sudden Cardiac Death: Data from the Paris Sudden Death Expertise Center Registry]. Rev Prat 2015;65:916-8.

[4] Luc G, Baert V, Escutnaire J, et al. Epidemiology of out-of-hospital cardiac arrest: A French national incidence and mid-term survival rate study. Anaesth Crit Care Pain Med 2018.

[5] Marijon E, Bougouin W, Cariou A, et al. Sudden death expertise centre: a multi disciplinary approach for sudden death. Arch Cardiovasc Dis 2011;104:555-7.

[6] Stromsoe A, Svensson L, Axelsson AB, et al. Improved outcome in Sweden after out-ofhospital cardiac arrest and possible association with improvements in every link in the chain of survival. Eur Heart J 2015;36:863-71.

[7] Wong MK, Morrison LJ, Qiu F, et al. Trends in short- and long-term survival among out-ofhospital cardiac arrest patients alive at hospital arrival. Circulation 2014;130:1883-90.

[8] Hasselqvist-Ax I, Riva G, Herlitz J, et al. Early cardiopulmonary resuscitation in out-of-hospital cardiac arrest. N Engl J Med 2015;372:2307-15.

[9] Chan PS, Krumholz HM, Nichol G, Nallamothu BK, American Heart Association National Registry of Cardiopulmonary Resuscitation Investigators. Delayed time to defibrillation after inhospital cardiac arrest. N Engl J Med 2008;358:9-17.

[10] Field JM, Hazinski MF, Sayre MR, et al. Part 1: executive summary: 2010 American Heart Association Guidelines for Cardiopulmonary Resuscitation and Emergency Cardiovascular Care. Circulation 2010;122:S640-56.

[11] Neumar RW, Eigel B, Callaway CW, et al. American Heart Association Response to the 2015 Institute of Medicine Report on Strategies to Improve Cardiac Arrest Survival. Circulation 2015;132:1049-70.

[12] Hubert H, Tazarourte K, Wiel E, et al. Rationale, methodology, implementation, and first results of the French out-of-hospital cardiac arrest registry. Prehosp Emerg Care 2014;18:511-9. 
[13] Karam N, Marijon E, Dumas F, et al. Characteristics and outcomes of out-of-hospital sudden cardiac arrest according to the time of occurrence. Resuscitation 2017;116:16-21.

[14] LOI n 2018-527 du 28 juin 2018 relative au défibrillateur cardiaque. Available at: https://www.legifrance.gouv.fr/affichTexte.do?cidTexte=JORFTEXT000037116260\&categorie Lien=id.

[15] Jost D, Degrange H, Verret C, et al. DEFI 2005: a randomized controlled trial of the effect of automated external defibrillator cardiopulmonary resuscitation protocol on outcome from outof-hospital cardiac arrest. Circulation 2010;121:1614-22.

[16] Perkins GD, Handley AJ, Koster RW, et al. European Resuscitation Council Guidelines for Resuscitation 2015: Section 2. Adult basic life support and automated external defibrillation. Resuscitation 2015;95:81-99.

[17] Hallstrom AP, Ornato JP, Weisfeldt M, et al. Public-access defibrillation and survival after outof-hospital cardiac arrest. N Engl J Med 2004;351:637-46.

[18] Marijon E, Bougouin W, Tafflet M, et al. Population movement and sudden cardiac arrest location. Circulation 2015;131:1546-54.

[19] Page RL, Joglar JA, Kowal RC, et al. Use of automated external defibrillators by a U.S. airline. N Engl J Med 2000;343:1210-6.

[20] Valenzuela TD, Roe DJ, Nichol G, Clark LL, Spaite DW, Hardman RG. Outcomes of rapid defibrillation by security officers after cardiac arrest in casinos. N Engl J Med 2000;343:12069.

[21] Department of Health and Human Services, General Services Administration. Public Access Defibrillation Guidelines. Available at: https://foh.psc.gov/whatwedo/AED/HHSAED.ASP [accessed date: 13th September 2015].

[22] Nichol G, Hallstrom AP, Kerber R, et al. American Heart Association report on the second public access defibrillation conference, April 17-19, 1997. Circulation 1998;97:1309-14.

[23] Weisfeldt ML, Kerber RE, McGoldrick RP, et al. American Heart Association Report on the Public Access Defibrillation Conference December 8-10, 1994. Automatic External Defibrillation Task Force. Circulation 1995;92:2740-7.

[24] Borjesson M, Serratosa L, Carre F, et al. Consensus document regarding cardiovascular safety at sports arenas: position stand from the European Association of Cardiovascular 
Prevention and Rehabilitation (EACPR), section of Sports Cardiology. Eur Heart J 2011;32:2119-24.

[25] Priori SG, Blomstrom-Lundqvist C, Mazzanti A, et al. 2015 ESC Guidelines for the management of patients with ventricular arrhythmias and the prevention of sudden cardiac death: The Task Force for the Management of Patients with Ventricular Arrhythmias and the Prevention of Sudden Cardiac Death of the European Society of Cardiology (ESC). Endorsed by: Association for European Paediatric and Congenital Cardiology (AEPC). Eur Heart $\mathrm{J}$ 2015;36:2793-867.

[26] Weisfeldt ML, Kerber RE, McGoldrick RP, et al. Public access defibrillation. A statement for healthcare professionals from the American Heart Association Task Force on Automatic External Defibrillation. Circulation 1995;92:2763.

[27] Fleischhackl R, Roessler B, Domanovits H, et al. Results from Austria's nationwide public access defibrillation (ANPAD) programme collected over 2 years. Resuscitation 2008;77:195200.

[28] Berdowski J, Blom MT, Bardai A, Tan HL, Tijssen JG, Koster RW. Impact of onsite or dispatched automated external defibrillator use on survival after out-of-hospital cardiac arrest. Circulation 2011;124:2225-32.

[29] Karam N, Narayanan K, Bougouin W, et al. Major regional differences in Automated External Defibrillator placement and Basic Life Support training in France: Further needs for coordinated implementation. Resuscitation 2017;118:49-54.

[30] Brooks B, Chan S, Lander P, Adamson R, Hodgetts GA, Deakin CD. Public knowledge and confidence in the use of public access defibrillation. Heart 2015;101:967-71.

[31] Hansen CM, Wissenberg M, Weeke $P$, et al. Automated external defibrillators inaccessible to more than half of nearby cardiac arrests in public locations during evening, nighttime, and weekends. Circulation 2013;128:2224-31.

[32] Dahan B, Jabre P, Karam N, et al. Optimization of automated external defibrillator deployment outdoors: An evidence-based approach. Resuscitation 2016;108:68-74.

[33] Pulver A, Wei R, Mann C. Locating AED Enabled Medical Drones to Enhance Cardiac Arrest Response Times. Prehosp Emerg Care 2016;20:378-89. 
[34] Claesson A, Fredman D, Svensson L, et al. Unmanned aerial vehicles (drones) in out-ofhospital-cardiac-arrest. Scand J Trauma Resusc Emerg Med 2016;24:124.

[35] Zijlstra JA, Stieglis R, Riedijk F, Smeekes M, van der Worp WE, Koster RW. Local lay rescuers with AEDs, alerted by text messages, contribute to early defibrillation in a Dutch outof-hospital cardiac arrest dispatch system. Resuscitation 2014;85:1444-9.

[36] Derkenne C, Jost D, Briche F, Travers S, Tourtier JP, Paris Fire Brigade Cardiac Arrest Task Force. Letter by Derkenne et al. regarding the article, "The use of trained volunteers in the response to out-of-hospital cardiac arrest - the GoodSAM experience". Resuscitation 2018;125:e3.

[37] Smith CM, Lim Choi Keung SN, Khan MO, et al. Barriers and facilitators to public access defibrillation in out-of-hospital cardiac arrest: a systematic review. Eur Heart J Qual Care Clin Outcomes 2017;3:264-73.

[38] Lubin J, Chung SS, Williams K. An assessment of public attitudes toward automated external defibrillators. Resuscitation 2004;62:43-7.

[39] Fredman D, Svensson L, Ban Y, et al. Expanding the first link in the chain of survival Experiences from dispatcher referral of callers to AED locations. Resuscitation 2016;107:12934. 


\section{Figure legends}

Figure 1: Central illustration. The rate of AED use remains very low due to both AEDdeployment and bystanders-related issues. Several solutions can be envisaged, including the optimisation of AED deployment strategies, the use of drones, a better education of the population to BLS and a more poheminent role of EMS dispatcher in guiding bystanders to AED location and through AED use.

Figure 2. The Chain of Survival - a series of interventions which, when implemented in a timely manner, can increase the potential for surviving a sudden cardiac arrest; it begins with early recognition of an out-of-hospital sudden cardiac arrest and access to care, followed by early cardiopulmonary resuscitation (CPR), early defibrillation and early advanced care by emergency medical services and hospital personnel.

Figure 3. Association of out-of-hospital sudden cardiac arrest survival rate with the development of Public Access Defibrillation Programmes [29]. Departments were classified according to their investment in each arm of Public Access Defibrillation Programmes, with a high number of automated external defibrillators (AEDs) and basic life support (BLS)-educated inhabitants defined by a number above the median (22 AEDs per 100,000 inhabitants per $1000 \mathrm{~km}^{2}$ and 13,866 per 100,000 inhabitants, respectively). Survival rate was highest in departments where AED density and the proportion of BLS-educated individuals were both above the median. 
Table 1 Median distance between an out-of-hospital cardiac arrest and the nearest automated external defibrillator, according to different deployment strategies [32].

\begin{tabular}{|c|c|c|c|}
\hline & $\begin{array}{l}\text { Number } \\
\text { of AEDs }\end{array}$ & $\begin{array}{l}\text { Median [IQR] distance } \\
\text { to OHCA }(\mathrm{m})\end{array}$ & $\begin{array}{l}\text { Median [IQR] round-trip } \\
\text { walking time (minutes) }\end{array}$ \\
\hline Guidelines-based AED deployment strategy & 170 & $416[180-614]$ & $10[4-15]$ \\
\hline \multicolumn{4}{|l|}{ Mesh-based AED deployment strategy } \\
\hline \multicolumn{4}{|l|}{ Distance between AEDs (m) } \\
\hline 200 & 2169 & $110[70-144]$ & $3[2-3]$ \\
\hline 300 & 966 & $168[118-218]$ & $4[3-5]$ \\
\hline 400 & 546 & $226[168-284]$ & $5[4-7]$ \\
\hline 500 & 350 & 276 [203-346] & $7[5-8]$ \\
\hline 1000 & 85 & 535 [374-664] & $13[9-16]$ \\
\hline 1500 & 37 & $785[540-954]$ & 19 [13-23] \\
\hline 2000 & 20 & 991 [706-1246] & $24[17-30]$ \\
\hline \multicolumn{4}{|c|}{ Specific landmark-based AED deployment strategy } \\
\hline \multicolumn{4}{|l|}{ Public facilities } \\
\hline District councils & 20 & 1052 [669-1408] & $25[16-34]$ \\
\hline Post offices & 195 & 324 [210-452] & $8[5-11]$ \\
\hline Subway stations & 302 & 239 [145-369] & $6[3-9]$ \\
\hline Bike-sharing stations & 957 & 137 [78-201] & 3 [2-5] \\
\hline Pharmacies & 1466 & $142[74-215]$ & 3 [2-5] \\
\hline
\end{tabular}

AED: automated external defibrillator; IQR: interquartile range; OHCA: out-of-hospital cardiac arrest.

${ }^{\mathrm{a}}$ For an average walking speed of $1.4 \mathrm{~m} / \mathrm{s}$. 


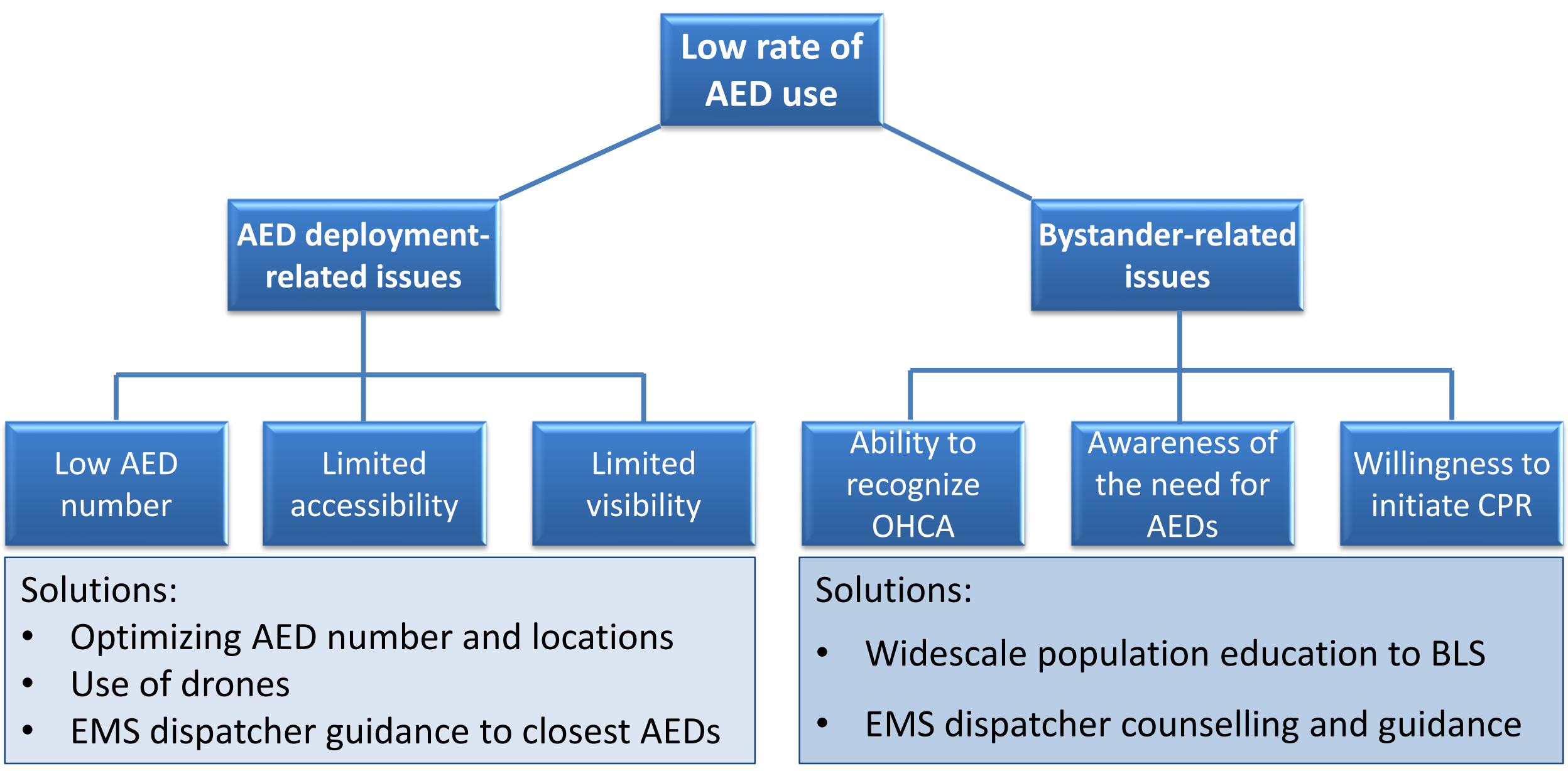




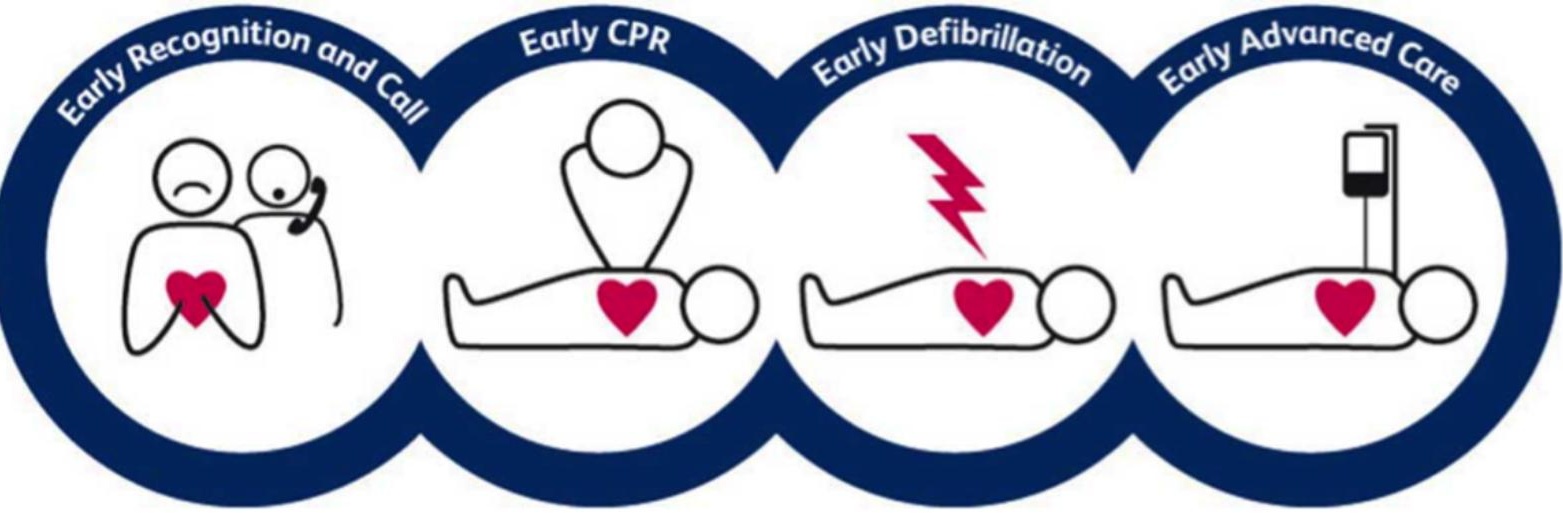



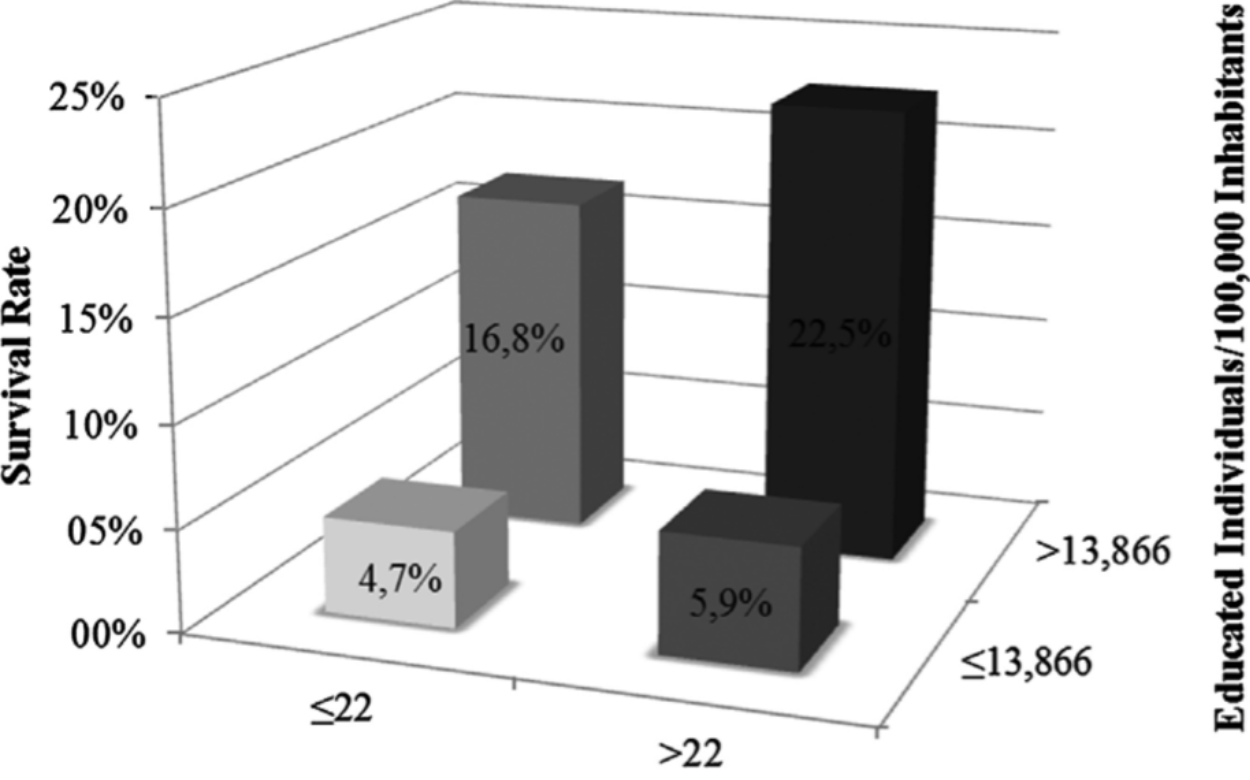
AED Number $/ \mathbf{1 0 0 , 0 0 0}$ Inhabitant $/ 1000$ km2 